\title{
PERANCANGAN SISTEM INFORMASI PENJUALAN VOUCHER GAME ONLINE BERBASIS DESKTOP PADA AREN.NET DI DEPOK
}

\author{
Angling Ananditya ${ }^{1}$, Sriyono ${ }^{2}$, Sepni Yanti ${ }^{3}$ \\ Program Studi Informatika, Fakultas Teknik dan Ilmu Komputer, Universitas Indraprasta PGRI \\ Jalan Raya Tengah No. 80, Kelurahan Gedong, Pasar Rebo, Jakarta Timur \\ Email: angling29ananditya@gmail.com, sriyono13@gmail.com, sepniyanti@gmail.com
}

\begin{abstract}
Abstrak
Tujuan Penelitian adalah untuk membuat sistem berbasis desktop yang efisien dan dapat membantu kinerja warnet pada saat transaksi. Metode penelitian yang digunakan oleh peneliti adalah deskriptif kualitif yaitu bertujuan untuk memberikan gambaran sistematik dan akurat mengenai fakta, sifat, dan hubungan antara fenomena yang diteliti dan berusahan untuk menekankan pada pemecah masalah aktual dengan cara mengumpulkan, menyajikan, atau menginterprestasikan serta menganalisis data dan informasi yang relevan untuk memberikan gambaran yang cukup jelas pada objek penelitian.
\end{abstract}

Kata Kunci: Sistem Informasi, Penjualan, Desktop, Java.

\begin{abstract}
The purpose of research is to create an efficient desktop-based system that can help internet cafe performance at the time of transaction. The research method used by researchers is a descriptive of qualifications that aims to provide a systematic and accurate picture of the facts, properties, and relationships between the phenomena researched and proposed to emphasize the problem solver By collecting, presenting or interpreting and analyzing the relevant data and information to provide a reasonably clear picture of the research object.
\end{abstract}

Keyword: Information Systems, Sales, Desktop, Java.

\section{PENDAHULUAN}

Seiring dengan berkembangnya teknologi informasi, muncul berbagai macam layanan yang dapat memenuhi akan informasi. Peran serta teknologi informasi menjadikan pengolahan informasi menjadi sangat mudah. Tidak dapat dipungkiri, pengolahan data menjadi informasi pada sebuah perusahaan yang dikelola sangat baik dapat membantu serta menunjang kegiatan manajemen dan operasional dengan penerapan sistem informasi.

Dalam upaya meningkatkan mutu pelayanan suatu informasi dan mempercepat proses penjualan dan pembuatan laporan maka Aren.Net harus menggunakan sistem komputerisasi dalam suatu proses penjualan sehingga proses pekerjaan akan tertib, serta dapat memberikan informasi yang cepat dan akurat. Setelah melihat dan menganalisis prosedur penelitian, peneliti menemukan beberapa permasalahan yang dapat mempengaruhi kinerja terhadap sistem yang ada. Adapun beberapa masalah yang dihadapi dalam sistem saat ini adalah proses pencatatan data dan transaksi penjualan masih dilakukan dengan cara penelitian pada buku pencatatan, sehingga sering terjadi kerangkapan data ataupun tidak tercatatnya data oleh operator. Proses pencatatan data dan transaksi penjualan hanya tercatat pada sebuah buku, sehingga sering terjadi kerusakan data, bahkan kehilangan data yang mengakibatkan kesulitan dalam membuat laporan. Proses dalam pencatatan data transaksi penjualan di Aren.Net masih bersifat manual dengan cara di catat di buku, sehingga mengakibatkan proses pencarian data transaksi penjualan dilakukan dengan cara mencari dalam arsip-arsip transaksi penjualan. Penyimpanan dokumen data voucher game online dan data transaksi penjualan disimpan dalam bentuk yang terpisah. Menyebabkan proses pembuatan laporan transaksi penjualan membutuhkan banyak waktu.

Berdasarkan permasalahan diatas maka tujuan dari penelitian ini adalah membuat rancangan sistem aplikasi berbasis desktop pada Aren.Net. Membuat sistem informasi penjualan yang terkomputerisasi. Membuat sistem yang efektif untuk memudahkan dalam melakukan transaksi. Manfaat dari penelitian ini adalah diharapkan dapat menambah pengetahuan dan wawasan bagi 
para pembaca, menjadi refrensi pada penelitian yang dilakukan peneliti selanjutnya, dan mengembangkan keterlampilan, kemampuan, dan ilmu pengetahuan guna memperoleh gambaran yang sesungguhnya, sehingga dapat membuka wawasan tentang peranan komputer. Menurut Rizky (2011), perancangan adalah sebuah proses untuk berbicara sesuatu yang akan dikerjakan dengan menggunakan teknik yang bervariasi serta didalamnya melibatkan deskripsi tentang komponen dan juga keterbatasan yang akan dialami dalm proses pengerjaanya. Sedangkan Subhan (2012), menjelaskan bahwa perancangan sistem merupakan proses spesifikasi baru berdasarkan rekomendasi hasil analisis sistem.

Sistem adalah sebagai kumpulan atau grup dari bagian atau komponen apapun baik fisik maupun non fisik yang saling berhubungan satu sama lain dan bekerja sama secara harmonis untuk mencapai satu tujuan tertentu (Azhar, 2013), sedangkan menurut beberapa peneliti lainnya seperti Sutabri (2012) bahwa sistem merupakan sekelompok unsur yang erat hubungannya satu dengan yang lain, yang berfungsi bersama-sama untuk mencapai tujuan tertentu. Informasi merupakan hasil pengolahan data dari satu atau berbagai sumber yang kemudian diolah sehingga memberikan nilai, arti dan manfaat. Salah satu aspek yang membutuhkan sistem untuk mengelola proses bisnis adalah Penjualan. Menurut Phadermrod et al. (2019), penjualan merupakan aktivitas memperjualbelikan barang dan jasa kepada konsumen. Selain itu pendapatan yang berasal dari penjualan produk perusahaan, disajikan setelah dikurangi potongan penjualan dan retur penjualan.

Sistem informasi merupakan suatu perkumpulan data yang terorganisasi beserta tata cara penggunaanya yang mencakup lebih jauh dari pada sekedar penyajian. Istilah tersebut menyiratkan suatu maksud yang ingin dicapai dengan jalan memilih dan mengatur data serta menyusun tata cara penggunaanya. Keberhasilan suatu sistem informasi yang diukur berdasarkan keserasian dan mutu data, pengorganisasian data, dan tata cara penggunaanya. Diagram alir data (DAD) selama ini merupakan alat pembuatan model yang memungkinkan profesional sistem untuk menggambarkan sistem sebagai suatu jaringan proses fungsional yang dihubungkan satu sama lain dengan alur data, baik secara manual maupun komputerisasi. Krismiaji (2015), dalam bukunya yang berjudul "Sistem Informasi Akuntansi", yang dimaksud kamus data adalah. "Kamus data adalah salah satu komponen kunci dalam sistem manajemen database adalah file khusus yang disebut kamus data (data dictionary). Dalam Sukamto et al.(2013), Entity Relationship Diagram (ERD) adalah pemodelan awal basis data yang akan dikembangkan berdasarkan teori himpunan dalam bidang matematika untuk pemodelan basis data relasional. Dan menurut Indrajani (2011), normalisasi adalah teknik dengan melakukan sebuah pendektan bottom-up yang digunakan dalam membantu mengidentifikasikan hubungan.

Membangun sebuah sistem diwujudkan melalui reprsentasi algoritma kedalam Bahasa pemograman. Salah satu Bahasa pemograman yang sering digunakan adalan Java. Bahasa pemrograman java adalah bahasa pemrograman berorentasi objek (PBO) atau Object Oriented Programming (OOP), Java bersifat netral, tidak bergantung pada suatu platform, dan mengikuti prinsip WORA (Write Once and Run Anywhere). Menurut Raharjo (2011), MySQL merupakan RDBMS atau server database yang mengelola database dengan cepat menampung dalam jumlah sangat besar dan dapat di akses oleh banyak user. Dalam Wahana (2015), iReport adalah tools yang memudahkan anda dalam pembuatan laporan, iReport biasanya digunakan dalam bahasa pemrograman Java.

\section{PENELITIAN RELEVAN}

Sakses Simbolon melakukan penelitian yang berjudul Perancangan Sistem Aplikasi Penjualan Sepeda Motor Bekas Berbasis Java di Showroom Harapan Jaya Motor Cibinong Bogor (Simbolon, n.d.). Melakukan penelitian terhadap aplikasi penjualan sepeda motor bekas mencakup data konsumen, data motor dan transaksi penjualan, yang bertujuan untuk mempermudah dan mengelola data konsumen, data motor, dan transaksi penjualan di Showroom Harapan Jaya agar pekerjaan menjadi efektif, efesien dan akurat serta membantu dalam menyelesaikan permasalahan pekerjaan yang berkenan dengan pengolahan data, agar dapat terealisasikan dengan tepat waktu.

Arif Sutisna melakukan penelitian yang berjudul Sistem Informasi Penjualan SparePart Motor Berbasis Java di PT. Sarana Baja Motor (Sutisna, n.d.). Melakukan Penelitian Terhadapat sistem informasi penjualan sparepart motor berbasis Java di PT Sarana Baja Motor yang bertujuan untuk 
mempermudah saat pencarian data barang, pengolahan data pelanggan dan data penjualan sparepart motor di PT Sarana Baja Motor agar pekerjaan menjadi efektif serta membantu menyelesaikan permasalahan pada sistem penjualan yang ada di PT Sarana Baja Motor agar pekerjaan dapat terealisasikan dengan tepat waktu.

Stephanie Surja, Rini Wongso melakukan penelitian yang berjudul Perancangan Sistem Informasi Penjualan Pada PT. Selatan Jaya Prima Perkasa (Surja \& Wongso, n.d.). Desain, implementasi, persediaan dan penjualan ini adalah sebagai sarana untuk memperoleh, mempercepat kinerja karyawan, mempermudah karyawan dalam mencari stok, dengan adanya desain implementasi stok barang dan penjualan ini pembuatan laporan bisa dilakukan dengan cepat dan tepat, mempermudah informasi kepada pihak pimpinan PT. Selatan Jaya Prima Perkasa untuk mengetahui data transaksi penjualan beserta laporan keuangan PT. Selatan Jaya Prima Perkasa.

\section{METODE PENELITIAN}

Tempat penelitian peneliti lakukan pada Aren.Net di Depok yang beralamatkan di Jl. Mahakam No. 33 Kel. Baktijaya, Kec. Sukmajaya, Kota Depok, Jawa Barat 16418. Metode penelitian yang digunakan adalah metode Research and Development (R\&D), metode penelitian yang selanjutnya akan di singkat menjadi R\&D di gunakan untuk menghasilkan produk tertentu, dan menguji ke efektifan produk tersebut.

Dalam penyusunan penelitian ini, peneliti melakukan pendekatan studi kasus dengan metode penelitian deskriptif kualitif yaitu bertujuan untuk memberikan gambaran sistematik dan akurat mengenai fakta, sifat dan hubungan antara fenomena yang diteliti dan berusaha untuk menekankan pada pemecahan masalah aktual dengan cara menumpulkan, menyajikan, atau menginterprestasikan serta menganalisis data dan informasi yang relevan untuk memberikan gambaran yang cukup jelas atas objek penelitian kemudian menarik kesimpulan dari keadaan yang ada pada Aren.Net di Depok.

Peneliti melakukan metode pengumpulan data untuk mendapatkan suatu data yang cukup dengan cara pengumpulan bahan-bahan keterangan dan data yang berhubungan dengan judul penelitian penelitian ini, sehingga tidak menyimpang dari pokok permasalahan. Observasi, yaitu metode untuk mendapatkan data dengan melakukan pengamatan langsung, pencatatan, dan pengumpulan data-data terhadap proses kerja sistem yang berjalan pada Aren.Net di Depok. Wawancara, yaitu melakukan pengumpulan data dengan melakukan tanya jawab dan tinjauan kepada operator yang bertugas pada Aren.Net di Depok mengenai penelitian ini. Studi Pustaka, mempelajari beberapa buku, sarana perpustakaan, dan catatan-catatan kuliah. Metode pengembangan sistem yang digunakan adalah metode Waterfall, dengan tahapan sebagai berikut:

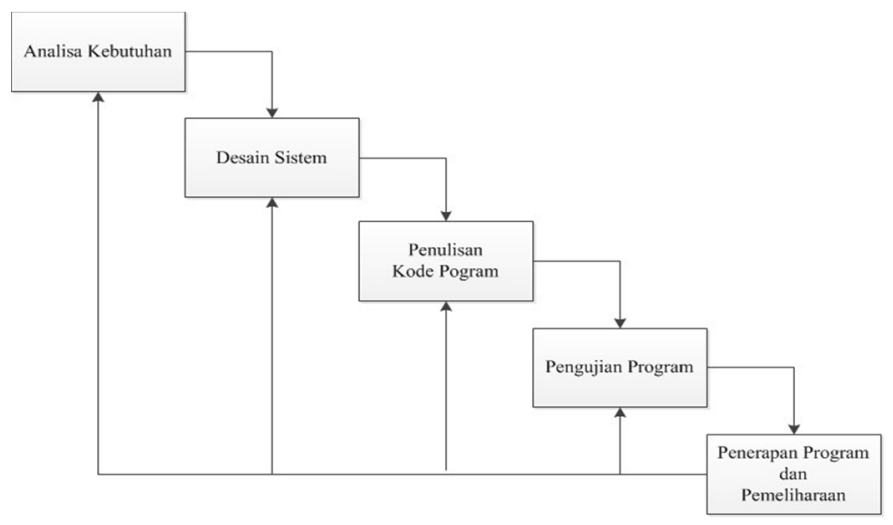

Gambar 1 Metode Waterfall

(Sumber: Pressman RS, 2010)

\section{HASIL DAN PEMBAHASAN}

Berikut ini adalah hasil analisis, perancangan, dan keluaran dari penelitian Perancangan Sistem Informasi Penjualan Voucher Game Online Berbasis Desktop Pada Aren.Net di Depok: 


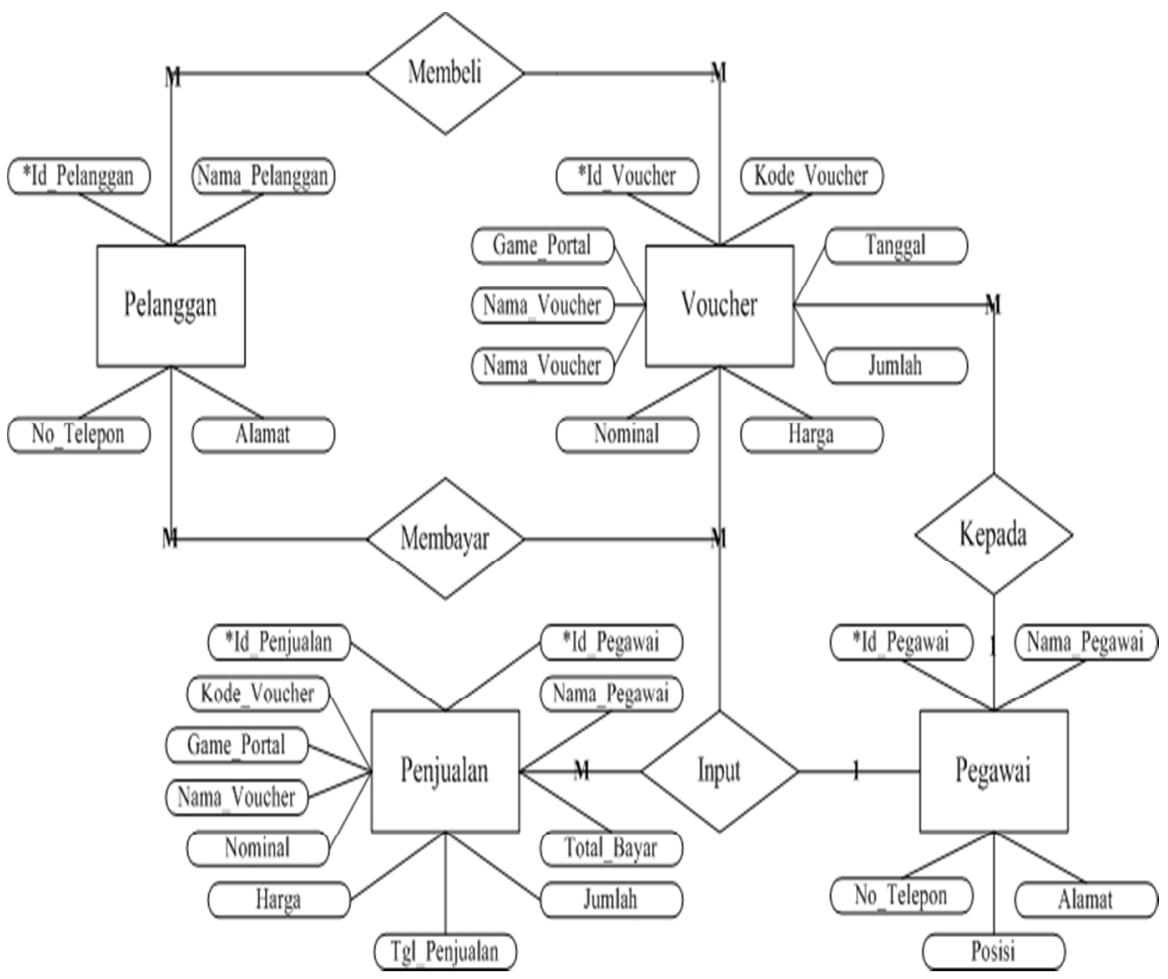

Gambar 2 Entity Relationship Diagram

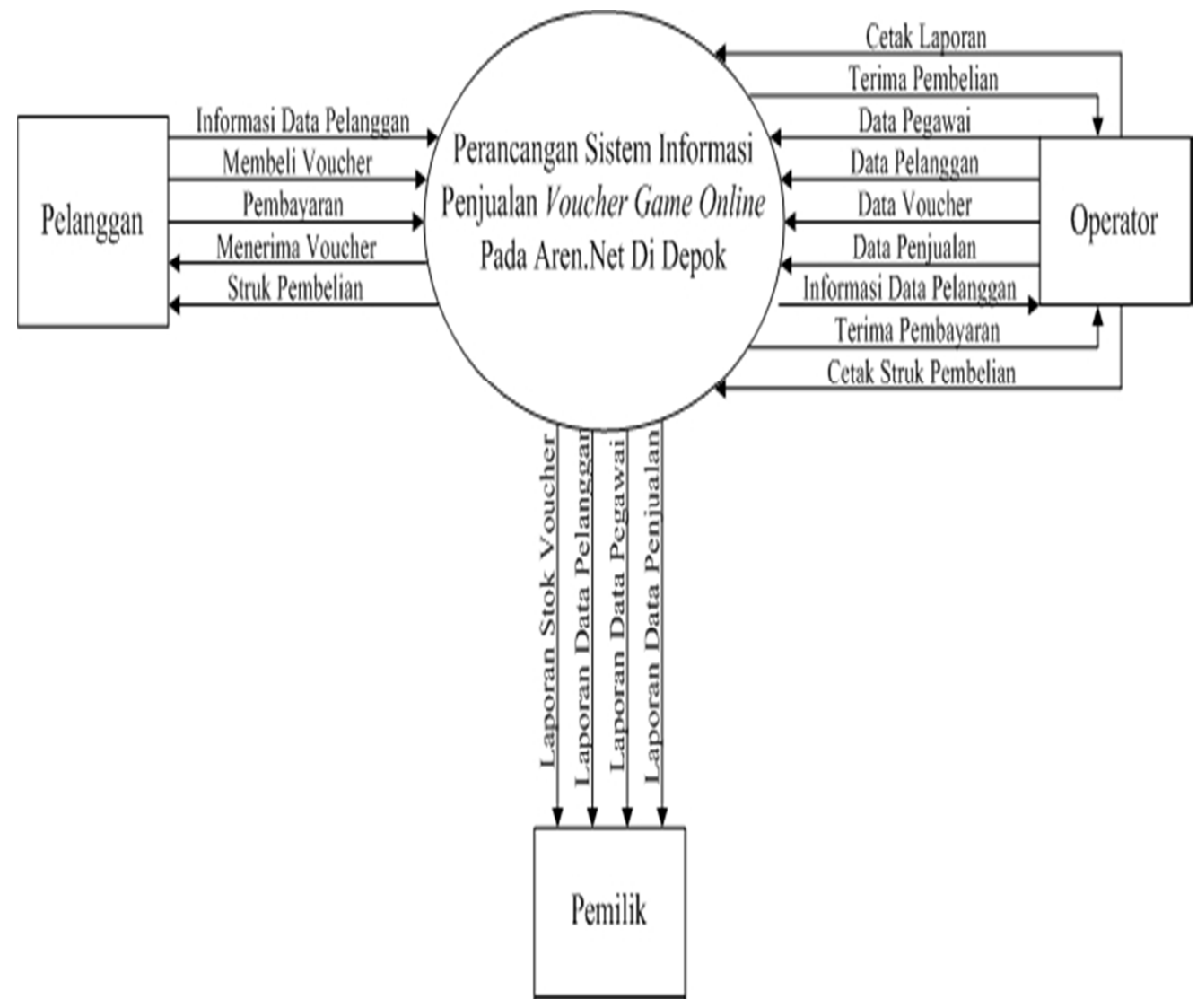

Gambar 3. Diagram Konteks 


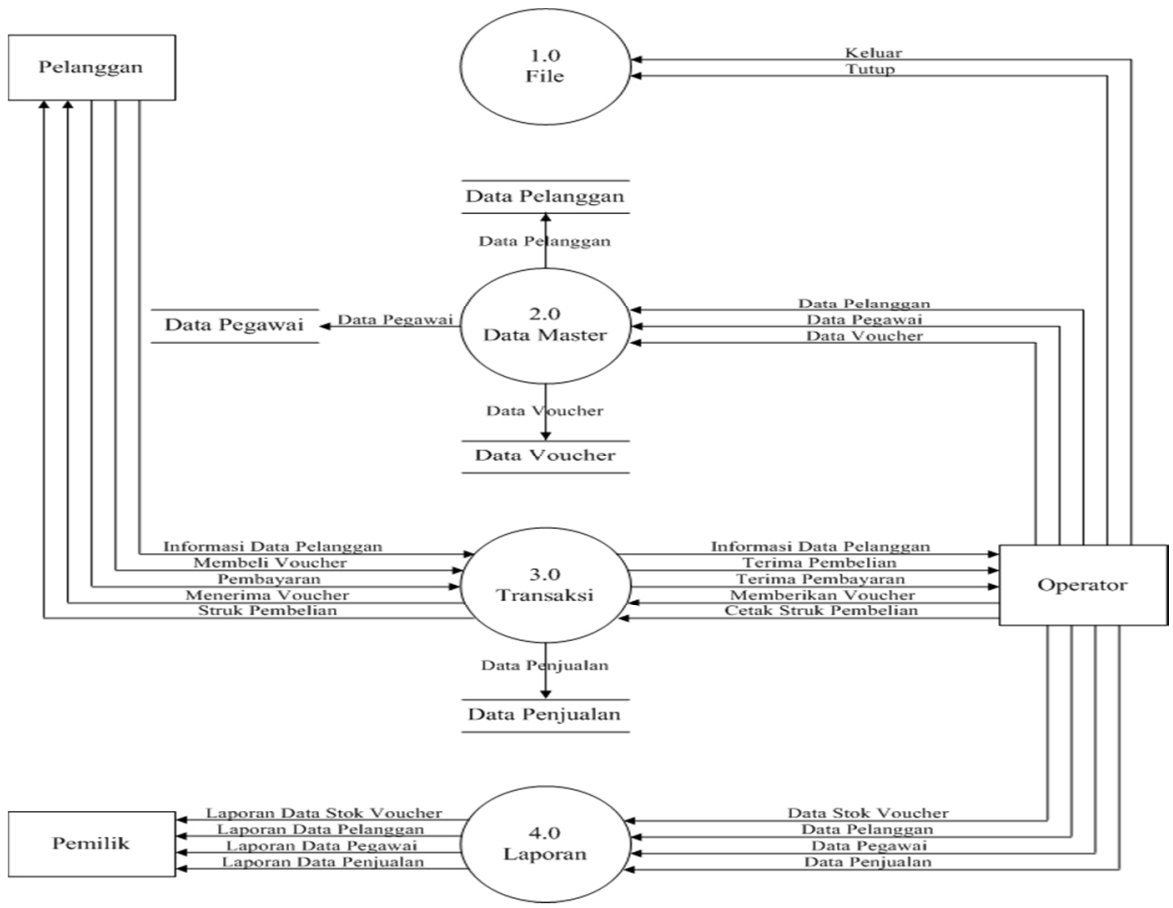

Gambar 4. Diagram Nol

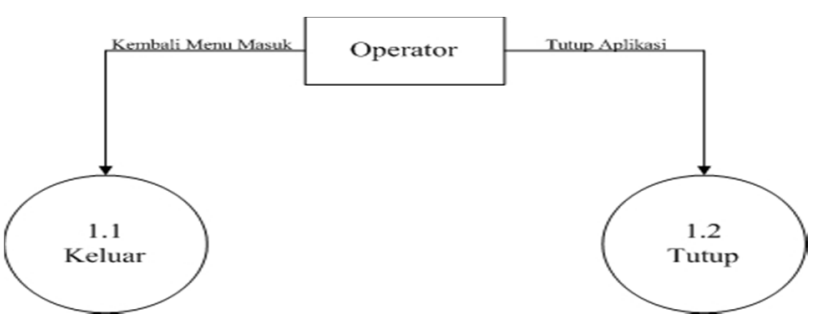

Gambar 5 Diagram Rinci Level 1 Proses 1 File

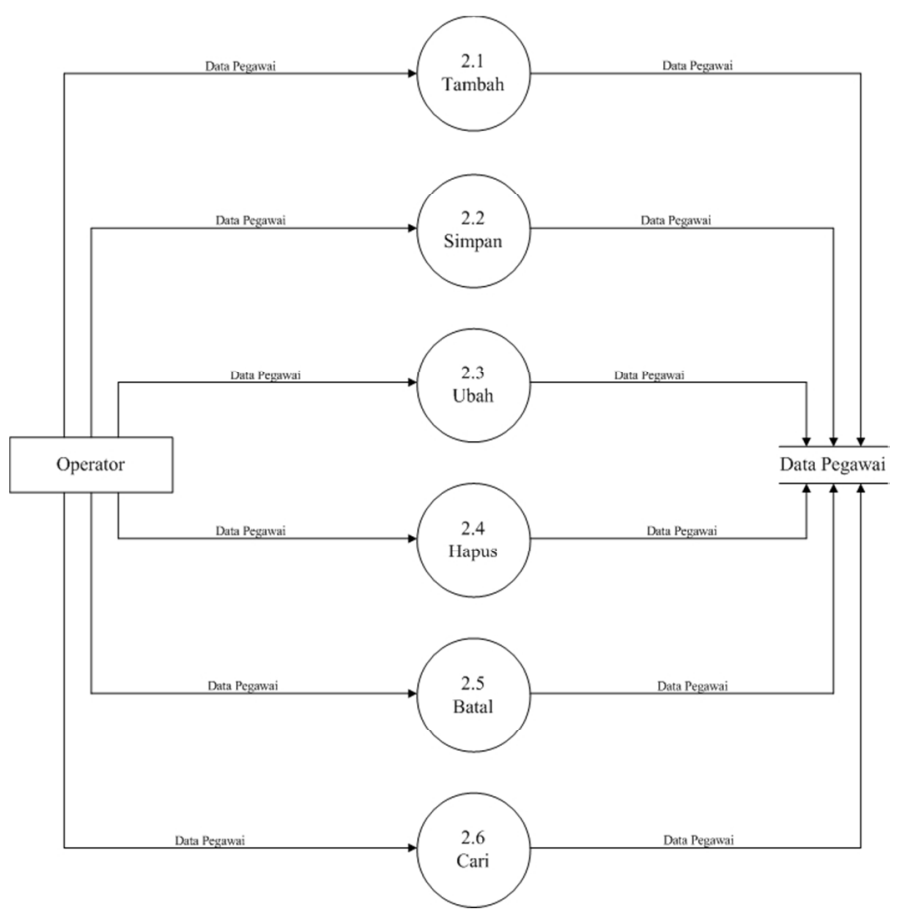

Gambar 6. Diagram Rinci Level 1 Proses 2 Data Pegawai 


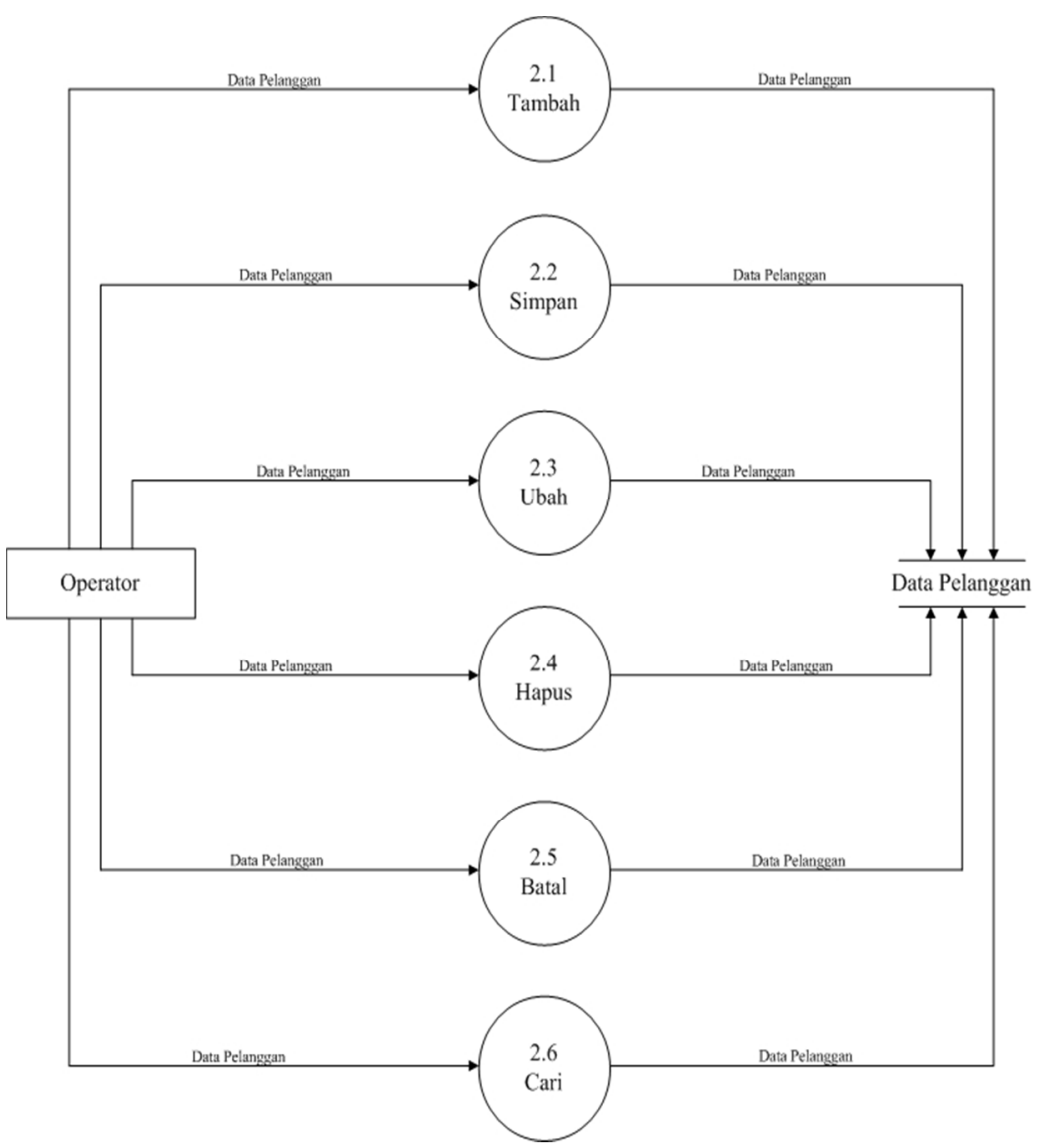

Gambar 7. Diagram Rinci Level 1 Proses 2 Data Pelanggan

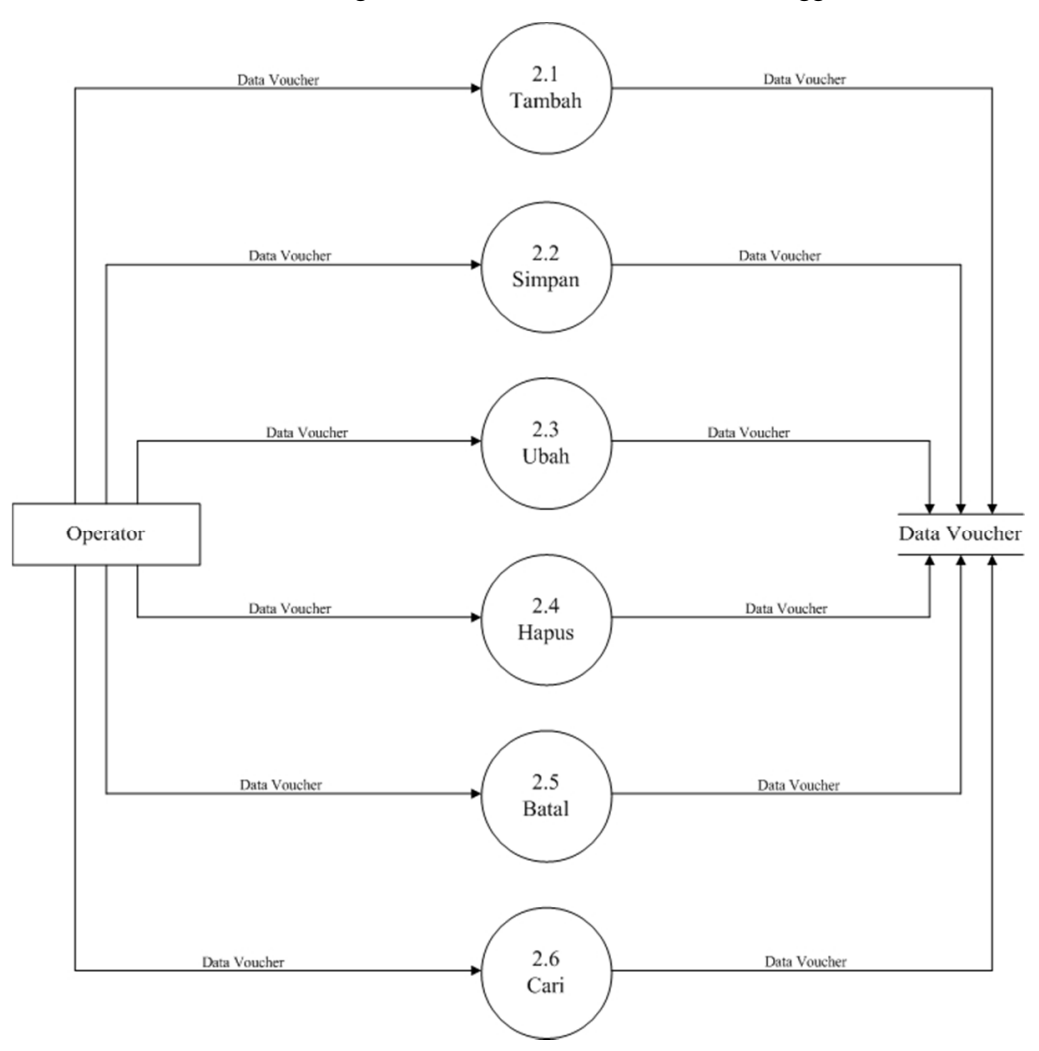

Gambar 8. Diagram Rinci Level 1 Proses 2 Data Voucher 


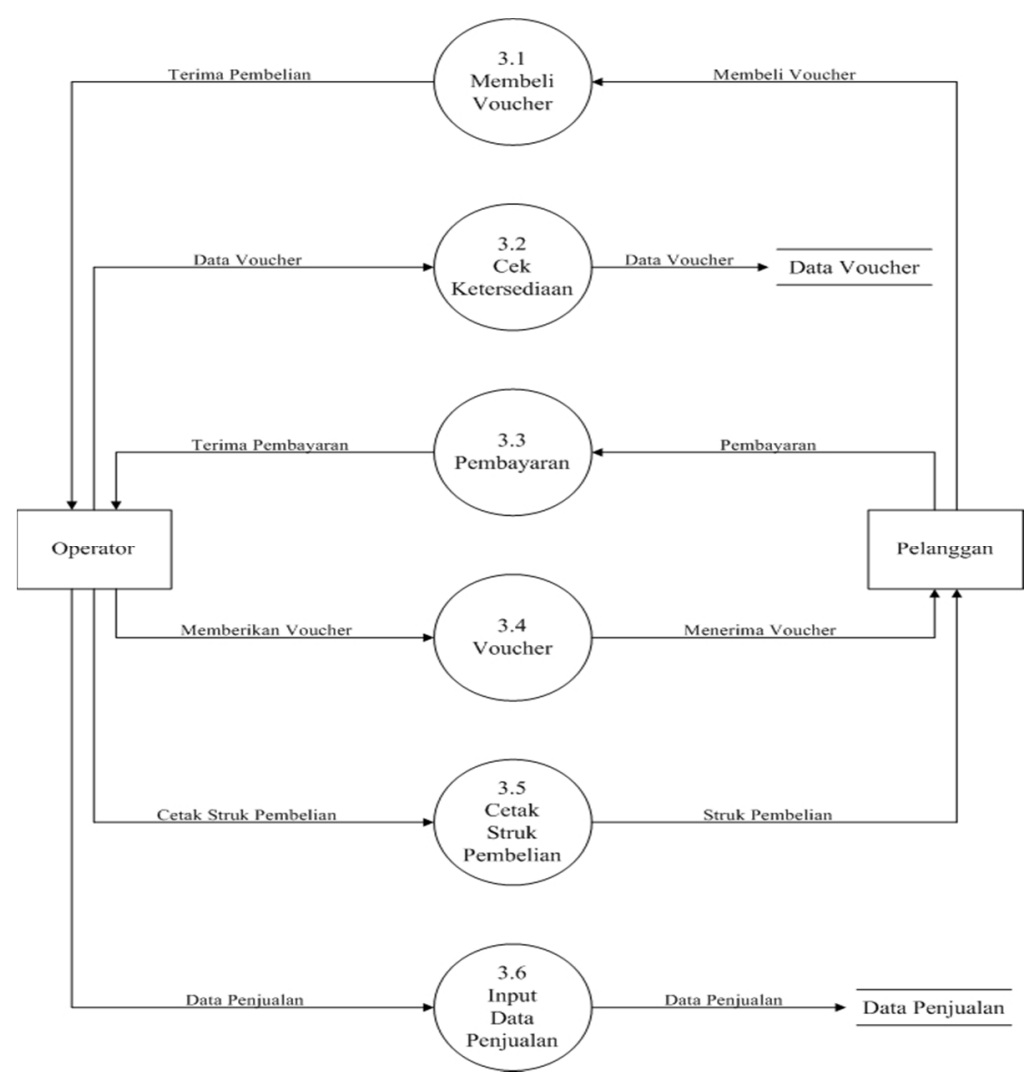

Gambar 9. Diagram Rinci Level 1 Proses 3 Penjualan

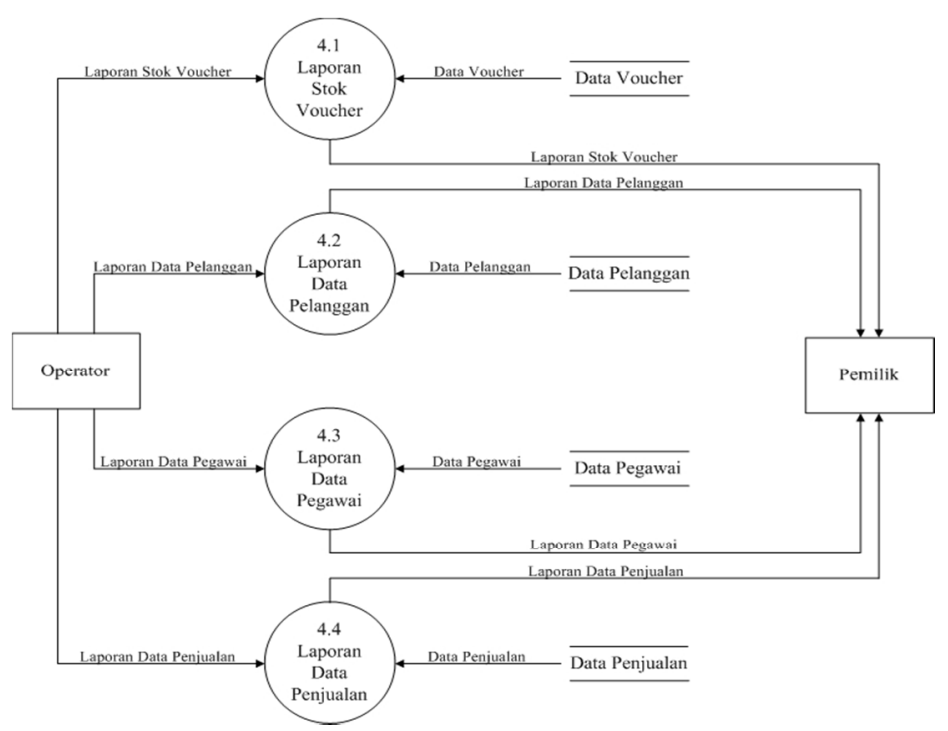

Gambar 10. Diagram Rinci Level 1 Proses 4 Laporan

Operator bisa melakukan keluar aplikasi untuk kembali ke menu masuk yang bertujuan untuk masuk dengan hak akses lainnya. Operator juga dapat melakukan tutup aplikasi secara menyeluruh. Operator akan melakukan input data pegawai jika ada penambahan pegawai. Jika ada pelanggan yang ingin membeli voucher maka operator harus menambahkan data pelanggan kedalam database. Data voucher akan di input oleh operator yang bertujuan untuk penambahan stok voucher.

Operator melakukan pembuatan laporan serta mencetaknya untuk diberikan kepada pemilik setiap sebulan sekali. Baik itu laporan stok voucher game online, data pegawai, penjualan voucher game online, maupun data pelanggan.

Aren.Net memiliki aturan-aturan bisnis, di antaranya adalah pemilik akan melakukan penginputan 
baru untuk data user dan data pegawai ke dalam database. Selanjutnya untuk data pelanggan dan data stok voucher game online akan di input oleh operator. Operator akan mengecek ketersediaan voucher game online saat ada pelanggan yang membeli voucher game online. Pelanggan menanyakan dan memilih voucher game online sesuai yang ingin dibeli kepada operator. Setelah itu operator melakukan penginputan data penjualan ke dalam database. Pelanggan selanjutnya melakukan proses pembayaran voucher game online yang harus dibayar sesuai dengan harga yang telah ditentukan. Setelah itu operator melakukan cetak struk penjualan untuk diberikan kepada pelanggan. Operator melihat seluruh data dalam database yang akan dibuatkan laporan di setiap akhir bulan untuk diserahkan kepada pemilik.

\section{SIMPULAN}

Simpulan yang di dapat adalah, proses transaksi penjualan voucher menjadi efektif, karena di sistem ini sudah otomatis tersedia data voucher dan stok voucher. Proses transaksi sudah terkomputerisasi, sehingga dapat mempermudah dan mempercepat waktu pekerjaan dalam pengolahan data penjualan voucher. Antarmuka yang sederhana dapat mempermudah user dalam mempelajari sistem ini.

\section{DAFTAR PUSTAKA}

Azhar, S. (2013). Sistem Informasi Akuntansi. Lingga Jaya.

Indrajani. (2011). Perancangan Basis Data dalam All in 1. PT Elex Media Komputindo.

Krismiaji. (2015). Sistem Inormasi. In Sistem Informasi Akuntansi.

Phadermrod, B., Crowder, R. M., \& Wills, G. B. (2019). International Journal of Information Management ImportancePerformance Analysis based SWOT analysis. International Journal of Information Management, 44, 194-203. https://doi.org/10.1016/j.ijinfomgt.2016.03.009

Raharjo, B., \& Raharjo, B. (2011). Belajar otodidak membuat database menggunakan MySQL / Budi Raharjo. 1. PANGKALAN DATA - PENGELOLAAN. MYSQL (PROGRAM KOMPUTER),Belajar Otodidak Membuat Database Menggunakan MySQL / Budi Raharjo. https://doi.org/2011

Rizky, S. (2011). Konsep Dasar Rekayasa Perangkat Lunak. In Konsep Dasar Rekayasa Perangkat Lunak.

Simbolon, S. (n.d.). Perancangan Sistem Aplikasi Penjualan Sepeda Motor Bekas Berbasis Java di Showroom Harapan Jaya Motor Cibinong Bogor.

Subhan, M. (2012). Analisa PErancangan Sistem. In Analisa perancangan sistem.

Sukamto, Ariani, R., \& Shalahuddin, M. (2013). Modul Pembelajaran Rekayasa Perangkat Lunak (Terstruktur dan Berorientasi Objek).

Surja, S., \& Wongso, R. (n.d.). Perancangan Sistem Informasi Penjualan Pada PT. Selatan Jaya Prima Perkasa.

Sutabri, T. (2012). Analisis Sistem Informasi. In Analisa Sistem Informasi.

Sutisna, A. (n.d.). Sistem Informasi Penjualan SparePart Motor Berbasis Java di PT. Sarana Baja Motor.

Wahana, K. (2015). Membangun Sistem Informasi Java dengan NetBeans dan MySQL. Andi Ofset. 